\title{
PERBANDINGAN METODE SEASONAL ARIMA DAN METODE EXPONENTIAL SMOOTHING DALAM MERAMALKAN KUNJUNGAN WISATAWAN MANCANEGARA KE BALI
}

\author{
Ni Putu Ayu Dewi Cahyantari ${ }^{1 \S}$, I Wayan Sumarjaya ${ }^{2}$, I Nyoman Widana ${ }^{3}$ \\ ${ }^{1}$ Program Studi Matematika, Fakultas MIPA - Universitas Udayana [Email: dewicahyantari17@gmail.com] \\ ${ }^{2}$ Program Studi Matematika, Fakultas MIPA - Universitas Udayana [Email: sumarjaya@unud.ac.id] \\ ${ }^{3}$ Program Studi Matematika, Fakultas MIPA - Universitas Udayana [Email: nwidana@yahoo.com] \\ ${ }^{\S}$ Corresponding Author
}

\begin{abstract}
Tourism is one of the main sectors in increasing a country's economy. For this reason, an estimate of tourist visits to Bali is needed so that it can be used as a benchmark for development and development in the tourism sector. Forecasting the number of foreign tourists coming to Bali using the Seasonal ARIMA method produces an MSE value of 1,250,276,526. While the Winter's Exponential Smoothing method obtained 1,291,150,258. The results of the forecast for the number of foreign tourists coming to Bali in 2020 using the SARIMA method are 588,980, 653,740, 659,817 (January-March 2020).
\end{abstract}

Keywords: SARIMA, Exponential Smoothing, Tourism, Bali

\section{PENDAHULUAN}

Peramalan merupakan kegiatan memprediksi sesuatu menggunakan data terdahulu atau pada masa lalu dengan tujuan mengantisipasi keadaan dan dapat memperkecil peluang suatu kesalahan terjadi. Salah satu bidang yang penting untuk diprediksi adalah bidang pariwisata.

Sektor utama peningkatkan ekonomi suatu negara salah satunya ialah Pariwisata. Perkembangan pariwisata negara akan memiliki keterkaitan dengan jumlah wisatawan yang melakukan kunjungan ke negara tersebut dan Bali memiliki potensi keunikan tradisi dan budaya masyarakatnya yang menjadikan daya tarik bagi wisatawan. Sehingga perlu dilakukan suatu peramalan untuk mengetahui perkembangan kunjungan wisatawan pada tahun-tahun berikutnya agar dapat menjadi ukuran untuk pengembangan dan pembangunan dalam sektor kepariwisataan.

Metode SARIMA dan Exponential Smoothing merupakan beberapa metode yang bisa digunakan dalam meramalkan data yang terdapat unsur data musiman. Metode SARIMA merupakan metode peramalan dengan perhitungan ARIMA dengan pola musiman, sedangkan metode Exponential Smoothing dengan cara pemulusan eksponensial. Kedua metode ini memiliki kesamaan yaitu data yang akan digunakan memiliki unsur musiman sehingga hasil peramalan yang akan diperoleh bisa menghasilkan nilai yang tidak jauh berbeda.

Dengan penjelasan yang diberikan, penulis berkeinginan untuk meneliti pertumbuhan kunjungan wisatawan agar mendapatkan model, peramalan, dan perbandingan menggunakan Metode SARIMA dan Metode Exponential Smoothing.

\section{METODE PENELITIAN}

Penelitian menggunakan data dari bagian Pariwisata Badan Pusat Statistik Provinsi Bali yaitu data Jumlah Wisatawan Asing yang Datang ke Bali periode Januari 2015 sampai Desember 2019 pada website resmi Badan Pusat Statistika Bali yaitu https://bali.bps.go.id. Langkah-langkah dalam peramalan menggunakan metode SARIMA :

1) Mempersiapkan data jumlah kunjungan wisata asing ke Bali periode 2015-2019.

2) Melakukan uji stasioneritas pada data, pada saat data bersifat nonstasioner maka langkah yang bisa ditempuh ialah melakuka differensing dan transformasi data. Jika 
data stasioner maka dapat lanjut ke langkah berikutnya.

3) Melakukan plot ACF dan PACF untuk memperkirakan parameter model sementara.

4) Menentukan Model

5) Menentukan Parameter

6) Menguji Kesesuaian Model
a. Melakukan uji white noise
b. Melakukan uji normalitas
c. Menghitung nilai AIC jika terdapat dua atau lebih model yang sesuai.

7) Melakukan peramalan

Langkah-langkah dalam peramalan menggunakan metode Exponential Smoothing:

1) Mempersiapkan data jumlah kunjungan wisata asing ke Bali periode Januari 2015 sampai Desember 2019.

2) Menentukan parameter yang sesuai.

3) Menentukan nilai pemulusan.

4) Melakukan suatu peramalan

Membandingkan keakuratan ramalan yang diperoleh Metode Seasonal ARIMA dan Metode Exponential Smoothing dalam meramalakan kedatangan wisatawan ke bali.

\section{HASIL DAN PEMBAHASAN}

\section{Identifikasi Data}

Identifikasi data dilakukan untuk menjadi bahan acuan analisis tahap selanjutnya. Berikut tampilan data dalam grafik.

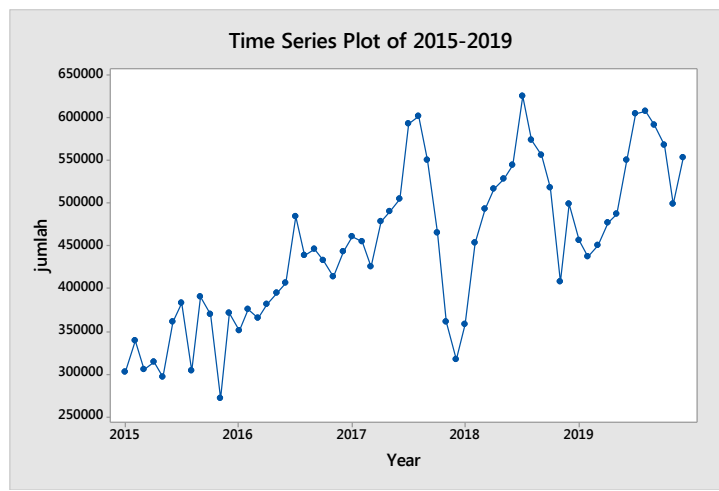

Gambar 1. Jumlah Wisatawan Asing yang Datang ke Bali

Gambar 1 menunjukkan bahwa data mengalami fluktuasi sehingga data bisa dikatakan tidak stasioner.

Namun untuk menguji apakah data stasioner atau tidaknya bisa menggunakan uji formal seperti uji ADF (Augmented Dickey Fuller) agar lebih pasti.

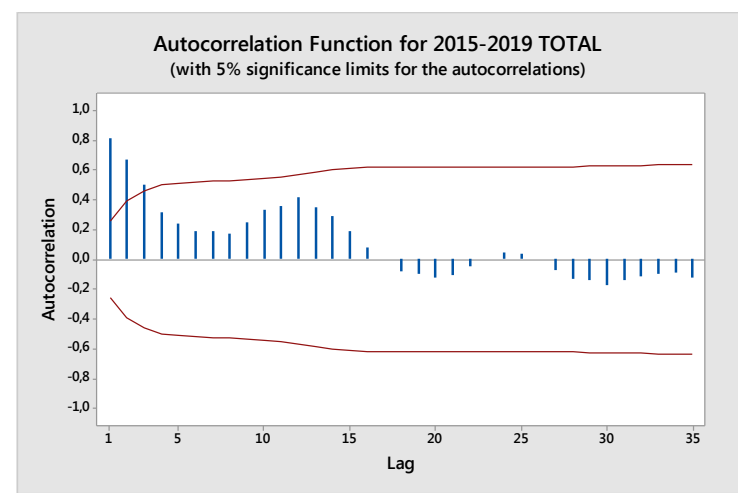

Gambar 2. Grafik ACF

Pada Gambar 2 dapat dilihat bahwa data mengalami autokorelasi atau bar (koefisien korelasi) pada gambar melebihi garis putusputus maka data nonstasioner.

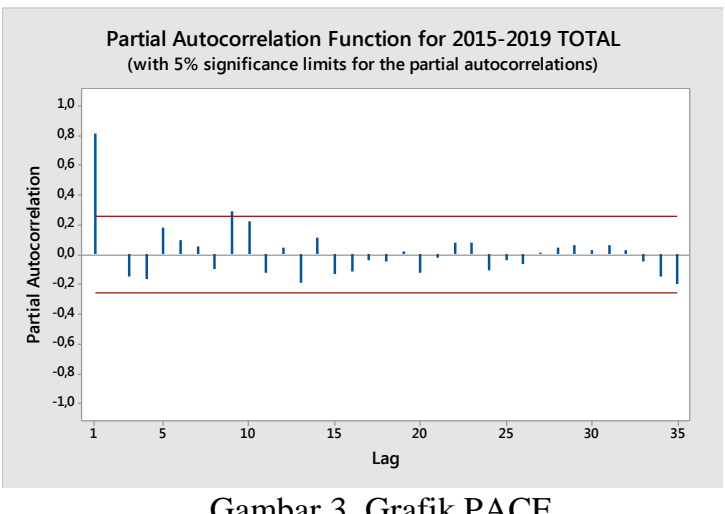

\section{Seasonal ARIMA (SARIMA)}

\section{Uji stasioneritas}

Pemeriksaan kestasioneran merupakan langkah awal dalam mengestimasi parameter model. Data nonstasioner akan membuat hasil estimasi dari model menjadi semu atau estimasi menjadi tidak tepat. Sehingga diperlukan pemeriksaan kestasioneran pada data. Cara yang digunakan untuk pemeriksaan kestasioneran data deret waktu yaitu dengan melakukan pengujian Augmented Dickey Fuller (ADF). Hipotesis yang digunakan pada uji ADF adalah:

$H_{0}: \beta=0$ (terdapat akar unit atau data tidak stasioner),

$H_{1}: \beta \neq 0$ (tidak terdapat akar unit atau data stasioner).

Hasil perhitungan statistik uji $t$ dengan menggunakan software $\mathrm{R}$ dapat dilihat pada Tabel 1. 
Tabel 1. Uji ADF

\begin{tabular}{lc}
\hline & Augmented Dickey Fuller test \\
\hline$t$ & $-4,8752$ \\
- statistic & 0,01 \\
\hline$p$-value & \\
\hline
\end{tabular}

Berdasarkan Tabel 1, diperoleh $-4,8752$ untuk nilai statistik uji $t$ dan 0,01 untuk $p$-value dengan taraf uji $\alpha=5 \%$. Karena $p$-value $<\alpha$, sehingga kriteria keputusannya adalah tolak $H_{0}$ yang artinya data bersifat stasioner.

\section{Menentukan Model}

Setelah data diketahui stasioner, selanjutnya mengidentifikasi orde $p, d, q$ dari model. Orde $p, q$ dapat diketahui dari korelogram (ACF) dan (PACF).

Gambar 4 menunjukan korelogram ACF musiman, data cut off setelah lag 1, sehingga kandidat model adalah SMA dengan $Q=1$. Sedangkan pada korelogram PACF musiman diketahui cut off setelah lag 1, sehingga kandidat model adalah SAR dengan $P=1$. Karena ACF dan PACF data differencing musiman sebanyak satu kali, diperoleh orde $D$ $=1$. Sehingga dugaan model sementara yaitu: $\operatorname{SARIMA}(2,1,2)(1,1,1)_{12}$.

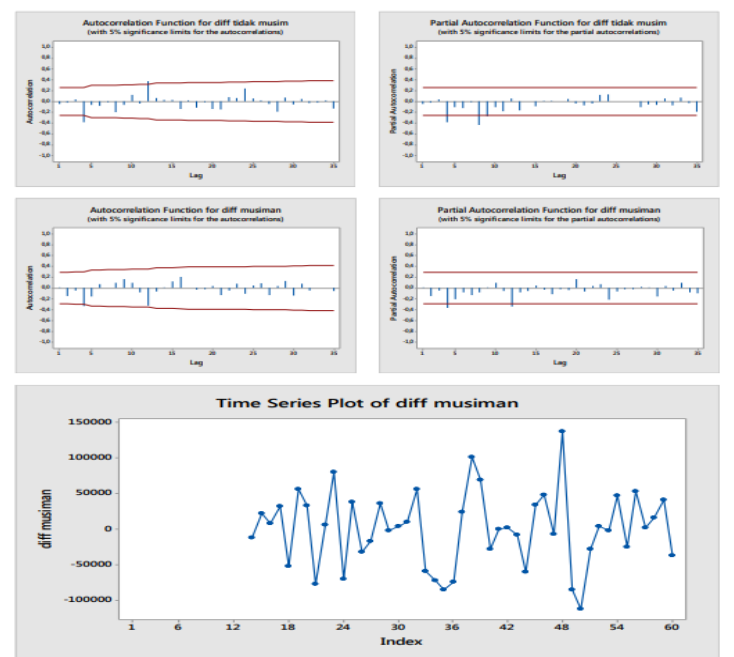

Gambar 4. Plot ACF dan PACF differencing pertama tidak musiman, ACF dan PACF differencing pertama tidak musiman dan musiman, dan plot differencing

\section{Estimasi Parameter}

Pendugaan parameter model yaitu melakukan penaksiran nilai parameter untuk semua model yang diduga. Setelah mendapatkan model, selanjutnya menduga parameter dari setiap model dengan melihat nilai $p$-value. Dikatakan $p$-value > 0,05 maka stasioner. Berikut diberikan hasil pendugaan parameter beberapa model dugaan menggunakan software minitab.

Tabel 2 Estimasi Parameter

\begin{tabular}{|l|l|c|}
\hline Model & $p$-value & Ket. \\
\hline \multirow{4}{*}{ ARIMA $(2,1,2)(1,1,1)_{12}$} & 0,326 & Tidak \\
\cline { 2 - 3 } & 0,931 & Tidak \\
\cline { 2 - 3 } & 0,019 & Ya \\
\cline { 2 - 3 } & 0,172 & Tidak \\
\cline { 2 - 3 } & 0,387 & Tidak \\
\cline { 2 - 3 } & 0,001 & Ya \\
\hline \multirow{3}{*}{ ARIMA $(1,1,1)(1,1,0)_{12}$} & 0,001 & Ya \\
\cline { 2 - 3 } & 0,002 & Ya \\
\cline { 2 - 3 } & 0 & Ya \\
\hline \multirow{2}{*}{ ARIMA $(0,1,0)(1,1,1)_{12}$} & 0,004 & Ya \\
\cline { 2 - 3 } & 0 & Ya \\
\hline
\end{tabular}

Dari model diatas terlihat dua model dari ketiga dugaan model yang diujikan memiliki parameter signifikan. Selanjutnya untuk model yang signifikan dilakukan uji white noise dan uji kenormalan.

\section{a) Uji White noise}

Kriteria daerah kritis untuk white noise adalah $H_{0}$ akan diterima jika nilai signifikansi $(p-$ value $)$ pada Ljung-Box lebih besar dari $\alpha$ $(p-$ value $>\alpha)$. Sebaliknya $H_{0}$ akan ditolak jika nilai signifikansi ( $p$-value) pada LjungBox lebih kecil dari $\alpha(p-$ value $<\alpha)$. Hasil uji ditampilkan dalam Tabel 3

Tabel 3 Uji White Noise

\begin{tabular}{|c|l|c|}
\hline \multirow{2}{*}{ Model } & \multicolumn{2}{|c|}{ Residu } \\
\cline { 2 - 3 } & Lag & $p-$ value \\
\hline \multirow{3}{*}{ ARIMA $(1,1,1)(1,1,0)_{12}$} & 12 & 0,310 \\
\cline { 2 - 3 } & 24 & 0,413 \\
\cline { 2 - 3 } & 36 & 0,698 \\
\hline \multirow{2}{*}{ ARIMA $(0,1,0)(1,1,1)_{12}$} & 12 & 0,489 \\
\cline { 2 - 3 } & 24 & 0,527 \\
\cline { 2 - 3 } & 36 & 0,839 \\
\hline
\end{tabular}




\begin{tabular}{|c|l|}
\hline Model & Kesimpulan \\
\hline \multirow{2}{*}{ ARIMA $(1,1,1)(1,1,0)_{12}$} & $H_{0}$ diterima \\
\cline { 2 - 2 } & $H_{0}$ diterima \\
\cline { 2 - 2 } ARIMA $(0,1,0)(1,1,1)_{12}$ & $H_{0}$ diterima \\
\cline { 2 - 2 } & $H_{0}$ diterima \\
\cline { 2 - 2 } & $H_{0}$ diterima \\
\hline & $H_{0}$ diterima \\
\hline
\end{tabular}

Dari Tabel 3 diatas kedua model yang diujikan yaitu $\operatorname{ARIMA}(1,1,1)(1,1,0)_{12}$ dan $\operatorname{ARIMA}(0,1,0)(1,1,1)_{12}$ memenuhi asumsi dari white noise.

b) Uji Normalitas

Hipotesis Uji Normalitas, data akan dikatakan normal untuk p-value >0,05. Residu dikatakan normal dapat dilihat dari grafik normal probability plot residu yang berada disekitar atau mengikuti garis diagonal. Dari gambar 5 dapat diasumsikan normal.

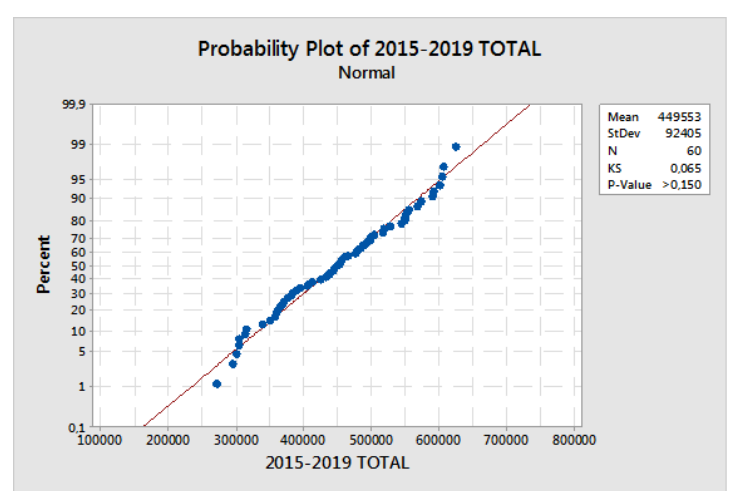

Gambar 5. Grafik uji kenormalan jumlah Wisatawan Asing yang Datang ke Bali

Karena ada dua model yang telah memenuhi asumsi yaitu stasioner, signifikansi, white noise, hingga berdistribusi normal, maka model terbaik dipilih dengan melihat nilai AIC terkecil. Pada Tabel 4 merupakan nilai AIC yang diperoleh dari setiap model.

Tabel 4. Nilai AIC

\begin{tabular}{|c|c|}
\hline Model & AIC \\
\hline ARIMA $(1,1,1)(1,1,0)_{12}$ & 889,76 \\
\hline ARIMA $(0,1,0)(1,1,1)_{12}$ & 889,47 \\
\hline
\end{tabular}

Berdasarkan Tabel 4 nilai AIC terkecil diperoleh oleh model ARIMA $(0,1,0)(1,1,1)_{12}$ dengan nilai 889,47 . Hasil untuk peramalan Jumlah Wisatawan Asing yang Datang ke Bali tahun 2020 menggunakan metode SARIMA ditunjukkan pada Tabel 5.
Tabel 5. Jumlah Wisatawan Asing yang Datang ke Bali tahun 2020 menggunakan metode SARIMA

\begin{tabular}{|c|c|}
\hline BULAN & RAMALAN \\
\hline Januari & 588.980 \\
\hline Februari & 653.740 \\
\hline Maret & 659.817 \\
\hline
\end{tabular}

\section{Metode Exponential Smoothing}

Dalam metode ini, akan digunakan batasan kriteria yaitu MSD (mean square deviation). Dalam mencari nilai alfa, beta, dan gama yang sesuai dapat melihat nilai MSD yang terkecil dengan cara trial and error. Tabel 6 berikut menampilkan beberapa uji coba nilai yang didapat.

Tabel 6 Estimasi Alfa, Beta, dan Gama

\begin{tabular}{|c|c|c|c|}
\hline Alfa & Beta & Gama & MSD \\
\hline 0,7 & 0,7 & 0,7 & 2.421 .366 .514 \\
\hline 0 & 0 & 0 & 2.616 .070 .156 \\
\hline 0,6 & 0,6 & 0,6 & 2.397 .282 .646 \\
\hline 0,5 & 0,5 & 0,5 & 2.557 .585 .753 \\
\hline 0,4 & 0,4 & 0,4 & 2.838 .940 .810 \\
\hline 0,3 & 0,3 & 0,3 & 2.772 .686 .910 \\
\hline 0,2 & 0,2 & 0,2 & 2.256 .425 .344 \\
\hline 0,8 & 0,8 & 0,8 & 2.549 .230 .039 \\
\hline 0,9 & 0,9 & 0,9 & 2.641 .612 .972 \\
\hline 1 & 1 & 1 & 2.685 .597 .608 \\
\hline 0,1 & 0,1 & 0,1 & 1.866 .690 .004 \\
\hline $\mathbf{0 , 9}$ & $\mathbf{0 , 1}$ & $\mathbf{0 , 1}$ & $\mathbf{1 . 2 9 1 . 1 5 0 . 2 5 8}$ \\
\hline 0,8 & 0,1 & 0,1 & 1.298 .047 .033 \\
\hline 0,7 & 0,1 & 0,1 & 1.327 .572 .660 \\
\hline 1 & 0,1 & 0,1 & 1.305 .182 .243 \\
\hline 0,6 & 0,1 & 0,1 & 1.381 .918 .936 \\
\hline & Minimal & $\mathbf{1 . 2 9 1 . 1 5 0 . 2 5 8}$ \\
\hline
\end{tabular}

Dengan melihat tabel tersebut maka dipilih nilai yang paling sesuai digunakan untuk konstanta pemulusan untuk data asli yaitu 0.9, kemudian untuk konstanta pemulusan pola tren diperoleh 0.1 , selanjutnya untuk konstanta pemulusan pola musiman didapat 0.1 dan mean square deviation (MSD) yang diperoleh sebesar 1.291.150.258. 
Gambar 6 menampilkan Grafik nilai fits model dan data.

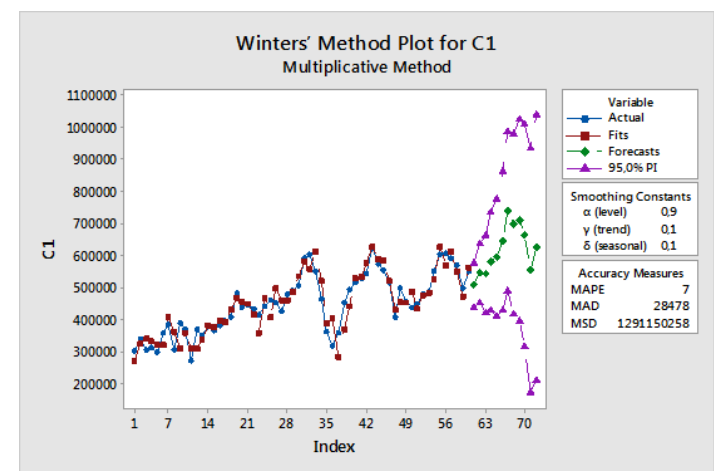

Gambar 6. grafik peramalan menggunaka metode Winter's Exponential Smoothing

Gambar 6 memperlihatkan grafik hasil dari peramalan. Garis biru pada gambar diatas merupakan data asli, pemulusan fits model peramalan terlihat dengan garis merah. Untuk hasil peramalan dapat dilihat pada garis berwarna hijau dan garis berwarna ungu merupakan batasan bawah dan batasan atas. Berdasarkan grafik, didapat persamaan untuk model multiplikatif Winter's Exponential Smoothing, yaitu:

1 Pemulusan exponensial data asli

$$
\begin{aligned}
L_{t}=0,9 \frac{Y_{t}}{S_{t-12}} & +(1-0,9)\left(L_{t-1}\right. \\
& \left.+T_{t-1}\right)
\end{aligned}
$$

2 Pemulusan pola tren

$$
T_{t}=0.1\left(L_{t}-L_{t-1}\right)+(1-0.1) T_{t-1}
$$

3 Pemulusan pola musiman

$$
S_{t}=0.1 \frac{Y_{t}}{L_{t}}+(1-0.1) S_{t-12}
$$

4 Ramalan periode ke- $p$

$$
\hat{\mathrm{Y}}_{t+p}=\left(L_{t}+p T_{t}\right) S_{t-12+p}
$$

Hasil untuk peramalan Jumlah Wisatawan Asing yang Datang ke Bali tahun 2020 menggunakan metode Exponential Smoothing pada Tabel 7.

Tabel 7. Jumlah Wisatawan Asing yang Datang ke Bali tahun 2020 menggunakan metode Exponential Smoothing

\begin{tabular}{|c|c|}
\hline BULAN & RAMALAN \\
\hline Januari & 507.823 \\
\hline Februari & 545.156 \\
\hline Maret & 542.700 \\
\hline
\end{tabular}

Hasil untuk peramalan ini berdasarkan peramalan secara teoritis. Karena adanya keadaan khusus saat ini yang menyebabkan penerbangan ditutup menyebabkan kunjungan wisatawan yang datang ke Bali tidak seperti biasanya.

\section{Perbandingan SARIMA dengan Winter's Exponential Smoothing}

Setelah data dianalisis dengan metode SARIMA dan Winter's Exponential Smoothing untuk meramalkan Jumlah Wisatawan Asing yang Datang ke Bali tahun 2020 didapatkan nilai Mean Square Error (MSE) atau Mean Square Devitiation (MSD) dari masing-masing metode. Hasil dari peramalan lebih akurat didapat jika menggunakan metode dengan hasil MSE terkecil untuk memperkecil tingkat kesalahan dalam peramalan. Hasil nilai MSE untuk metode Winter's Exponential Smoothing sebesar 1.291.150.258, sedangkan untuk metode Seasonal ARIMA adalah 1.250.276.526. Tabel 8 menampilkan hasil dari nilai MSE untuk setiap metode.

Tabel 8. Nilai MSE Setiap Metode

\begin{tabular}{|l|c|}
\hline \multicolumn{1}{|c|}{ METODE } & $\begin{array}{c}\text { MSE (Mean Square } \\
\text { Error) }\end{array}$ \\
\hline Seasonal ARIMA & 1.250 .276 .526 \\
\hline $\begin{array}{l}\text { Winter's Exponential } \\
\text { Smoothing }\end{array}$ & 1.291 .150 .258 \\
\hline
\end{tabular}

Peramalan akan lebih baik menggunakan metode Seasonal ARIMA model $\operatorname{ARIMA}(0,1,0)(1,1,1)_{12}$ dikarenakan nilai MSE lebih kecil dibanding metode Winter's Exponential Smoothing.

\section{KESIMPULAN}

Setelah dilakukan analisis terhadap Jumlah Wisatawan Asing yang Datang ke Bali menggunakan metode Seasonal ARIMA dan Exponential Smoothing, dapat simpulankan sebagai berikut:

1) Hasil analisis menggunakan metode SARIMA menghasilkan model $\operatorname{ARIMA}(0,1,0)(1,1,1)_{12}$. Sedangkan hasil yang diperoleh menggunakan metode Winter's Exponential Smoothing adalah $\alpha=0.9, \beta=0.1, \gamma=0.1$.

2) Hasil untuk peramalan ini berdasarkan peramalan secara teoritis. Karena adanya keadaan khusus saat ini yang menyebabkan penerbangan ditutup menyebabkan 
kunjungan wisatawan yang datang ke Bali tidak seperti biasanya. Hasil peramalan untuk bulan Januari dengan metode SARIMA adalah 588.980. Pada bulan Februari berjumlah 653.740, 659.817 merupakan hasil pada bulan Maret. Hasil dari menggunakan metode Winter's Exponential Smoothing pada bulan Januari adalah 507.823. Pada bulan Februari berjumlah $545.156,542.700$ merupakan hasil pada bulan Maret.

3) Peramalan dengan metode SARIMA menghasilkan nilai MSE 1.250.276.526. Untuk metode Winter's Exponential Smoothing yaitu 1.291.150.258. Sehingga metode Seasonal ARIMA dirasa lebih tepat untuk digunakan dalam meramalan Jumlah Wisatawan Asing yang Datang ke Bali tahun 2020 karena memiliki nilai MSE lebih kecil daripada metode Winter's Exponential Smoothing.

\section{DAFTAR PUSTAKA}

Adnyana, I. K., Sumarjaya, I. W., \& Sukarsa, I. K. (2016). Peramalan Jumlah Kunjungan Wisatawan Mancanegara yang Berkunjung ke Bali Menggunakan Fungsi Transfer. EJurnal Matematika , 5 (4), 139-147.

Badan Pusat Statistik Provinsi Bali . (19822019). Diambil kembali dari https://bali.bps.go.id/statictable/2018/02/09 /21/jumlah-wisatawan-asing-ke-balimenurut-bulan-1982-2019.html

Kusmanto, H. (2010). Analisis Perbandingan Peramalan Metode Seasonal Autoregressive Integrated Moving Average dan Triple Exponential Smoothing. Institut Pertanian Bogor, Skripsi.

Lestari, N., \& Wahyuningsih, N. (2012). Peramalan Kunjungan Wisata dengan Pendekatan Model SARIMA. Jurnal Sains dan Seni ITS , 1 (1), A29-A33.

Makridakis, S. G., Wheelwright, S. C., \& McGee, V. (1983). Forecasting Methods and Applications. New York: Wiley.
Munawaroh, A. N. (2010). Peramalan Jumlah Penumpang Pada Pt Angkasa Pura I (persero) Kantor Cabang Bandar Udara Internasional Adisutjipto Yogyakarta dengan Metode Winter's Exponensial Smoothing dan Seasonal ARIMA. Universitas Negeri Yogyakarta, Skripsi.

Shumway, R. H., \& Stoffer, D. S. (2011). Time Series Analysis and Its Application with $R$. New York: Springer.

Sihite, R. (2000). Tourism Industry (Kepariwisataan), . Surabaya: SIC.

Suwedayana, I. P., Sumarjaya, I. W., \& Suciptawati, N. L. (2016). Peramalan Jumlah Kunjungan Wisatawan Australia yang Berkunjung ke Bali Menggunakan Model Time Varying Parameter (TVP). EJurnal Matematika , 5 (3), 117-125.

Wei, W. W. (2006). Time Series Analysis Univariate and Multivariate methods Second Edition (Vol. 2). New York: Pearson Addison Wesley. 